\title{
The Effect of Childhood Bilectalism and Multilingualism on Executive Control
}

Kyriakos Antoniou, Kleanthes K. Grohmann, Maria Kambanaros, and Napoleon Katsos

\begin{abstract}
Several investigations report a positive effect of childhood bilingualism on executive control (EC). However, an issue that has remained largely unexamined is the role of the typological distance between the languages spoken by bilinguals. In the present study we focus on children who grow up with Cypriot Greek and Standard Modern Greek, two closely related varieties that differ from each other on all levels of language analysis (vocabulary, pronunciation, grammar). We compare the EC performance of such bilectal children to that of English-Greek multilingual children in Cyprus and Standard Modern Greek-speaking monolingual children in Greece. A principal component analysis on six indicators of EC revealed two distinct factors which we interpreted as representing working memory and inhibition. Multilingual and bilectal children exhibited an advantage over monolinguals that was evident across the EC system and emerged only after statistically controlling for their lower language proficiency. These results demonstrate that similar EC advantages as previously reported for 'true' bilingual speakers can be found in bilectal children, which suggests that minimal typological distance between the varieties spoken by a child suffices to give rise to advantages in EC. They further indicate that the effect of speaking more than one language or dialect on EC performance is located in overall EC ability without a particular component being selectively affected. This has implications for models of the locus of the bilingual advantage in EC performance. Finally, they show that the emergence of EC advantages in bilinguals is moderated by the level of their language proficiency.
\end{abstract}

Keywords: bilectalism; multilingualism; typological distance; executive control 


\section{Background}

\subsection{Introduction}

A growing body of research has recently focused on the relation between bilingualism and the development of specific cognitive systems, particularly language and executive control (henceforth, EC) (see, among others, Bialystok, 2001; Oller \& Eilers, 2002; Genesee \& Nicoladis, 2007; Nicoladis, 2008; Bialystok et al., 2009; Hilchey \& Klein, 2011; Adesope et al., 2012; Akhtar \& Menjivar, 2012; Siegal \& Surian, 2012; Grosjean \& Li, 2013; Kroll \& Bialystok, 2013; Barac et al., 2014; Paap, 2014). Two outcomes have been reported in this research: negative effects of bilingualism on aspects of language development and positive effects on domains of non-verbal cognitive functioning (Oller \& Eilers, 2002; Nicoladis, 2008; Bialystok et al., 2010; Adesope et al., 2012; Akhtar \& Menjivar, 2012). Regarding language, the most widely-reported correlate of bilingualism is vocabulary acquisition, with bilingual children typically exhibiting smaller vocabularies in each of their languages than comparable monolinguals. Non-linguistic cognitive correlates include an enhancement of EC skills in bilingual children.

In the present study we compare the EC performance of a group of bilectal children (to use the term introduced by Rowe \& Grohmann, 2013) speaking Cypriot Greek and Standard Modern Greek to that of multilingual and monolingual Greek-speaking children. The linguistic profile of bilectal children as speakers of two minimally distant (in terms of structural and lexical similarity) and genetically related linguistic varieties, offers a unique opportunity to address one of the pending questions in the literature on the cognitive effects of bilingualism - namely, whether close typological proximity between the language pairs spoken by bilinguals modulates these outcomes in any way.

\subsection{The effect of bilingualism on EC ability}

Bilingualism and its relation to non-linguistic cognitive functioning has been one of the most active areas of research in the last ten years (see Kroll \& Bialystok, 2013; Barac et al., 2014). A widely reported empirical finding of this research is an enhancement of EC skills in bilingual children (e.g. Bialystok, 1999; Carlson \& Meltzoff, 2008; Martin-Rhee \& Bialystok, 2008; Bialystok, 2011; Poarch \& van Hell, 2012; Morales et al., 2013; Calvo \& Bialystok, 2014; though see e.g. Morton \& Harper, 2007; Hilchey \& Klein, 2011; Duñabeitia et al., 2014; Paap, 2014). 
EC refers to a domain-general cognitive system in the prefrontal cortex that is critical for the flexibility and regulation of cognition and goal-directed behavior (Best et al., 2009; Best \& Miller 2010). Even though there is no broad consensus regarding its precise components and the degree to which they are related, a widely accepted framework is that proposed by Miyake et al. (2000). According to this account EC comprises three core cognitive processes that are distinguishable but yet moderately interrelated (the unity and diversity view): switching (the ability to flexibly switch between rules, representations or tasks), working memory ${ }^{\mathrm{i}}$ (the ability to simultaneously maintain and manipulate task-relevant information in mind), and inhibition (the ability to suppress dominant or automatic responses and to resolve conflict by suppressing irrelevant information). Recently, Miyake and Friedman (2012) refined this model by suggesting that there is no separable inhibition factor.

Bilingual advantages in EC performance have been observed throughout the first years of life, for infants (Kovacs \& Mehler, 2009), pre-schoolers (e.g. Carlson \& Meltzoff, 2008; Yang et al., 2011), and school-aged children (e.g. de Abreu et al., 2012). Advanced EC skills have been hypothesized to (at least partly) underlie bilingual children's superior performance in a wide variety of linguistic and even more importantly non-linguistic tasks, demonstrating a generalized bilingual cognitive advantage that extends beyond the linguistic domain: the Simon task (e.g. Martin-Rhee \& Bialystok, 2008; Poarch \& van Hell, 2012), the Attentional Networks task (e.g. Yang et al., 2011), the Stroop task (e.g. Poulin-Dubois et al., 2011), the Dimensional Change Card Sort task (Bialystok, 1999), false-belief and appearance-reality Theory of Mind tasks (e.g. Bialystok \& Senman, 2004; Goetz, 2003; Kovacs, 2008), and metalinguistic tasks where a distinction between form and meaning must be made (Bialystok, 1988), to name but a few examples. It is worth noting, however, that some researchers have raised concerns about the very validity of these cognitive benefits (e.g. Morton \& Harper, 2007; Duñabeitia et al., 2014; Paap \& Sawi, 2014; Paap, 2014; Paap et al., 2014), though it is not yet clearly understood why the effects do (not) appear in some studies.

Earlier work (e.g. Bialystok, 2001; Bialystok et al., 2009) proposed that the bilingual advantage in EC tasks is found in inhibition. However, subsequent researchers have considered alternative explanations. Costa et al. (2009) proposed that the bilingual advantage in interference tasks might be better characterized in terms of an enhanced executive system whose main responsibility is to monitor for the presence of conflict. On the other hand, recent work by Bialystok (2011) attributes the bilingual advantages to a better ability to coordinate or jointly recruit the different EC components (see also Kroll \& Bialystok, 2013). 


\subsection{The effect of typological similarity between the language pairs spoken by bilinguals on EC}

The available experimental evidence so far seems to support the view that any combination of languages, irrespective of degree of typological proximity, leads to EC benefits in bilinguals. In a recent meta-analysis of studies on the cognitive correlates of bilingualism, Adesope et al. (2010) reported that bilingualism had a statistically detectable effect on a combined score of attention and representation measures (including attentional control, problem-solving, abstract, and symbolic representation measures), irrespective of the language pairs spoken by bilinguals (including language pairs as diverse as English-French and English-Chinese). Their conclusion is that any combination of languages (and thus any degree of typological distance between two languages) can lead to general cognitive advantages in bilinguals. A similar conclusion was reached by Barac et al. (2014:13) in their critical review of the literature on the cognitive development of preschool-aged bilingual children (see also Barac \& Bialystok, 2012).

The results of the studies conducted by Costa et al. (2008; 2009), Garbin et al. (2010), Hernandez et al. (2010), and Hernandez et al. (2013) lend weight to the expectation that even bilectal speakers might show advantages in their EC skills. These studies compared the EC performance of Spanish-Catalan bilingual adults to that of Spanish monolinguals. Spanish and Catalan are two closely related Romance languages with a high degree of similarity on all levels (see Appendix B in Costa et al., 2008). As an indication of the lexical proximity between the two languages, Costa et al. (2008) report that $70 \%$ of the translation equivalents in the two languages could be considered cognates. Similarly, Ethnologue reports a lexical similarity of $85 \%$ between the two languages, exactly on the cut-off point for two varieties being dialects of the same language (Lewis et al., 2014; see Dialects under the Catalan language entry). ${ }^{\text {ii }}$

Costa et al. (2008) administered the adult version of the Attentional Networks Task (henceforth, ANT) and reported a bilingual advantage in the efficiency of two attentional networks: alerting and EC (Costa et al., 2008:82). Hernandez et al. (2010) found a bilingual advantage in EC using a Stroop-like task but no differences between bilinguals and monolinguals in the alerting attentional component using a visual cueing task. In a subsequent study, Costa et al. (2009) further explored the bilinguals' superior performance in the ANT and found a bilingual advantage in overall reaction times only in the highmonitoring versions of the task. The authors argue that their results indicate a positive 
bilingual effect on monitoring skills.

Garbin et al. (2010) administered a non-verbal switching test and reported that bilingual adults exhibited a significantly smaller switching cost than monolinguals that was evident in both accuracy and reaction times. In three subsequent experiments, however, Hernandez et al. (2013) failed to replicate the bilingual advantage in switching skills using various (more or less demanding) versions of a switching task. Rather, they reported a bilingual advantage only in the restart cost (experiment 1) and in overall reaction time performance (experiment 2). Hernandez et al. (2013) suggest that this pattern of results is consistent with a bilingual advantage in reactivating the relevant task-set and/or monitoring.

Overall, these studies - though conducted with adult participants and inconclusive with regards to the locus of the bilingual advantage in EC tasks - offer some preliminary evidence that an advantage in EC can be found even for bilinguals who speak two structurally and lexically close languages. In the next section we briefly describe the socio-linguistic situation in Greek-speaking Cyprus from where our sample of bilectal and multilingual children was drawn for the purposes of the study in this paper.

\subsection{The (socio-)linguistic situation in Greek-speaking Cyprus and the relation between Cypriot Greek and Standard Modern Greek}

The sociolinguistic situation in Greek-speaking Cyprus has been described as one of diglossia with the local vernacular, Cypriot Greek (henceforth, CG), acting as the low variety and Standard Modern Greek (henceforth, SMG), forming the high variety (Arvaniti, 2010; Rowe \& Grohmann, 2013; but see Auer, 2005; Karyolemou, 2006). CG is a non-standardized, nonorthographically-codified dialect of Greek (Newton 1972; Arvaniti 2010). SMG is the official, constitutionally recognized language of the Republic of Cyprus and it is also the language spoken by Hellenic Greeks in the Republic of Greece. The former variety is natively and naturalistically acquired by Greek Cypriot children, while the latter is acquired sequentially and mainly through formal education.

The diglossic character of the sociolinguistic situation in Cyprus implies that the two varieties enjoy strict functional separation with each variety associated with different and seldom overlapping domains of use and everyday situations. CG is used in informal settings and everyday face-to-face interactions, while SMG is employed in formal situationsparticularly in writing, public speech, and administration - and it is the main language used in the media. SMG is also by law the language of instruction in all state schools. 
The close typological similarity between CG and SMG can be operationalized as a function of three parameters: genetic relation as established by the traditional comparative method, lexical similarity, and mutual intelligibility. Concerning the first, CG and SMG are part of the Greek language family of Indo-European languages, Greek being an isolated group with no close relatives within the Indo-European languages (Lewis et al., 2014, under Classification in the Greek Language entry; see also Lyovin, 1997). Concerning the second, Ethnologue reports a lexical similarity of $84 \%-93 \%$ between the two varieties (Lewis et al., 2014, under Dialects in the Greek Language entry; see also Newton, 1972:111f.; Terkourafi, 2005:316). This is not to suggest that the two varieties do not exhibit differences (for additional discussion, see also Grohmann \& Leivada, 2012; Antoniou, 2014).

In terms of intelligibility, Greek Cypriots can readily understand SMG speakers due to their continuous exposure to SMG. Some degree of intelligibility is arguably present on the part of SMG speakers with some varieties of CG being more intelligible to them than others; Joseph (2010) describes mutual intelligibility as asymmetrical. CG is not a homogeneous language variety but it, too, shows internal language variability, ranging from basilectal local varieties (also called village speech by Newton, 1972, and Arvaniti, 2010) to an acrolectal urban variety (town speech in Newton, 1972, and Arvaniti, 2010). In fact, recent studies on the contemporary use of CG have argued that the latter variety has evolved into a panCyprian CG variety - a CG koiné that is rid of more local, more infrequent variety features, is more heavily influenced by SMG, and is considered by Greek Cypriots to be "the Cypriot variety par excellence" (Karyolemou \& Pavlou, 2001:119).

Arguably all three parameters suggest very close typological similarity between CG and SMG. In fact, when we take into account that our participants are speakers of the panCyprian CG variety it is likely that the lexical similarity will be at the highest margins within the range given by Ethnologue (84\%-93\%).

\subsection{The present study}

In this study a bilectal, a multilingual, and a monolingual group of children-all speakers of Greek - were administered a battery of EC tests. The similarities between the two varieties of Greek that were reviewed in the previous section make it likely that the bilectal children in the current study speak the most closely related varieties that have been investigated up to date. The comparison between multilingual and monolingual participants provides an opportunity to corroborate previously reported effects of speaking more than one language. 
Moreover, the contrast between bilectals and monolinguals enables us to examine the effect of bilectalism on executive functioning. In addition, the inclusion of multiple EC measures allows for the identification of potential component factors of the EC system and for the testing of different proposals regarding the locus of the bilingualii advantage in EC performance.

Finally, socioeconomic status, non-verbal fluid intelligence, and language proficiency were measured because these are factors that have been found in the literature to correlate with EC and can potentially confound the results of studies comparing bilingual and monolingual populations (for socioeconomic status, see e.g. Morton \& Harper, 2007; for nonverbal fluid intelligence, see e.g. Unsworth et al., 2014; for language proficiency, see e.g. Carlson \& Meltzoff, 2008). That said, contrasting the performance of bilectal and monolingual children allows for the control of various other factors that have been linked to bilingualism and/or cognitive performance. First, both the bilectal and monolingual children tested in this study come from local indigenous families (in Cyprus and Greece, respectively) with no immigration history. Additionally, factors such as cultural background or language of education are controlled by default because the two groups were recruited from countries that differ minimally in these respects (for a substantiation of this claim, see Antoniou, 2014).

\section{Method}

\subsection{Participants}

Participants consisted of 64 bilectal children (speakers of CG and SMG; 32 boys and 32 girls aged 4;5-12;2, mean age 7;7, SD 1;6 years), 47 multilingual children (bilectal in CG and SMG, also speakers of English and in some cases an additional language; 24 boys and 23 girls; ages 5;0-11;5, mean age 7;8, SD 1;8 years), and 25 monolingual children (speakers of SMG only; 15 boys and 10 girls aged 6;2-9, mean age 7;4, SD 0;9 years).

The multilingual children were recruited from private schools in the Republic of Cyprus. The schools offered English-speaking programs in accordance with the national curriculum of the United Kingdom. In these schools SMG was offered as a separate subject and all multilingual children were taught SMG for six hours per week. Eleven children in the multilingual group were exposed to additional language(s) at home besides Greek (CG, SMG) and English.

In the bilectal group, 36 children were recruited from a private primary school, eight from a private nursery school, and the remaining 20 from a local public primary school. All 
of these schools offered traditional Greek-speaking programs with limited exposure to a second language. None of the children included in the analyses had any exposure to or use of a language other than Greek at home.

The monolingual children were recruited from a private primary school in Athens, Greece. The language of instruction at the school was exclusively SMG. The parents were all monolingual SMG speakers who indicated speaking solely SMG to their children at home.

\subsection{Materials and procedure}

The same battery of tests was administered to every child in two sessions taking approximately 50-60 minutes each with the exception that the monolingual children and 17 of the bilectal children were additionally given the Peabody Picture Receptive Vocabulary Test (monolinguals in SMG and bilectals in $\mathrm{CG}$ ) at the end of the second session. The same bilectal children who took the Peabody Picture Vocabulary Test (PPVT) in CG also received the PPVT and a language comprehension test in SMG in a third session. Additional tests were given as part of another study.

\subsubsection{Socioeconomic status and language background questionnaire}

This questionnaire was an adaptation of and included elements from three questionnaires developed by other researchers: the Alberta Language Environment Questionnaire (ALEQ; Paradis, 2011), the Alberta Language Development Questionnaire (ALDeQ; Paradis et al., 2010), and the Family Affluence Scale (Currie et al., 1997).

In addition to information regarding the age of onset of exposure to each language and language use/input in certain specified situations (Antoniou, 2014), the questionnaire included items about the child's date of birth, gender, and the child's and parents' places of birth, among other details. It also required the parents to indicate whether their child had any educational, language, or other developmental difficulties.

Finally, the questionnaire requested information about the family's socioeconomic status via three measures: the Family Affluence Scale (henceforth, FAS) and the levels of maternal and paternal education. The FAS was administered as a measure of the family's wealth. Parents were also asked to indicate their level of education. There were four choices that corresponded to the highest level of education completed (numbers in parentheses indicate how each level was scored): junior high school (Gymnasium) (1), senior high school (Lyceum) (2), other professional training (3), and higher (post-secondary) education (4). 


\subsubsection{Language measures}

\section{Comprehension test}

This was part of a novel conversational test designed to examine children's ability to comprehend pragmatically implied meanings (henceforth, implicatures). The complete implicatures test was administered for the needs of another study (see Antoniou, 2014, for a more detailed description of the task). There were 15 test items, six practice items, and 48 filler items comprising a total of 69 trials. Participants' performance in the filler items, where no implicature was required for accurate responding, was taken as a measure of their language comprehension skills.

Items in this test were divided into three sections: a picture-selection and an act-out part administered using Microsoft PowerPoint software, and a binary judgment sub-test administered using the E-prime psychology software. All bilectal and multilingual children took the test in CG while the monolinguals received it in SMG. Seventeen of the bilectal children took the test in SMG as well. In both cases the items were pre-recorded by native speakers.

In the picture-selection part items required the understanding of short stories about a young male character named George. After hearing the pre-recorded story, the children were presented with two pictures and had to select the picture that showed how the story likely ended. Another three filler items had exactly the same format; however, in these cases, after listening to the target story, the children were presented with three pictures instead of two. The last three filler items from this section had a sentence-to-picture-matching format. Participants heard a pre-recorded sentence, they were then presented with two pictures, and were asked to select the one that matched the description.

Thirty additional (three practice and 27 test) items came from an action-based task (adapted from Pouscoulous et al., 2007) and involved the understanding of short sentences using the quantifiers some, all, and none (e.g. Some of the boxes have turtles). In this test the children were presented with Microsoft PowerPoint slides showing five boxes and a selection of animals (five elephants, five turtles, five dolphins, and five hippopotamuses). They were instructed that they would hear a voice describing the display and that they had to make the display match the description by using the mouse. Finally, another 23 items (two practice, 21 test) came from a binary judgment task that again required the understanding of short sentences using the quantifiers some, all, and none (e.g. There are stars on all of the cards). Participants were asked to decide whether a sentence was a correct or an incorrect description 
(by pressing a green- or a red-labeled key on the keyboard, respectively) of a visual display that included five cards depicting various items (stars, squares, or rings).

A total comprehension score was calculated for each child based on the filler items (48 items in total, with all practice items excluded) in the following way: scores in each subtest (picture-selection, act-out, binary judgment part) were transformed into $\mathrm{z}$ scores and the average of the three $\mathrm{z}$ scores was taken.

Peabody Picture Vocabulary Test-Revised (Dunn \& Dunn, 1981) (henceforth PPVT)

The SMG version of the task adapted from English by Simos et al. (2011) was administered as a test of receptive vocabulary. The test was further adapted to and recorded in CG by the first author, who is a native CG speaker. The adaptations in the CG version were minimal and included phonetic changes in the pronunciation of words (e.g. the SMG word ['çeri], meaning hand, was pronounced in $\mathrm{CG}$ as ['Jeri] or the SMG word ['krikos], meaning link, was pronounced with a geminate [k] as ['krik:os]) and also the substitution of SMG words with the corresponding CG words in cases where the SMG word was not part of the vocabulary used by Greek Cypriots or in cases where a more widely-used CG word existed (e.g. the word ['roða], meaning tire, which is used mainly by native SMG speakers was substituted with the word [tro'xos] which is used by both CG and SMG native speakers). This test was administered only to the monolingual children and a subset of 17 bilectal children. The former group of children received the task in SMG while the latter in both CG and SMG.

\section{Word Finding Vocabulary Test (henceforth WFVT) (Renfrew, 1995)}

The standardized Greek version (Vogindroukas et al., 2009) of the test was administered to assess expressive vocabulary. For the bilectal and multilingual children words in both CG and SMG were accepted as correct.

\subsubsection{Working memory tests}

The Backward Digit Span Task (Wechsler, 1949) (henceforth BDST)

The backward version of the Digit Span task was administered as a test of working memory. We further included two practice trials with a string of two digits before the actual test.

\section{The Corsi Blocks task}

This was an online computerized version of the Corsi Blocks task (Corsi, 1973). This test, as well as the Colour-Shape and Soccer tasks (see below), were developed online by Ellefson et 
al. (2011-2014). It was administered as a measure of visuo-spatial WM. The forward and backward parts of the test were administered separately with the forward condition always administered first. In each trial participants were presented with a display of nine boxes. In the forward condition, a blue circle appeared sequentially in a number of boxes and participants were instructed to click on the boxes where the circle had appeared and in the same order. The same happened in the backward condition but this time participants were instructed to click on the boxes where the circle had appeared in reverse order. Both conditions started with a trial where a circle appeared sequentially in two boxes. The number of circle appearances increased by one after every second trial (the highest level for forward condition was nine boxes while, for backward condition, it was seven boxes). There were two practice items with a sequence of two boxes in each condition. One point was awarded for each successful trial.

\subsubsection{Inhibition tests}

\section{The Soccer task}

This was an online Stop-Signal task (adapted from Logan, 1994). In each trial the children were presented with displays showing two soccer pitches. They were instructed to press the right arrow key on the keyboard when a ball appeared on the right pitch and the left arrow key when the ball appeared on the left pitch. Participants had to respond as quickly and as accurately as possible. In approximately $20 \%$ of the trials a whistle was heard. When hearing the whistle, children had to stop and not press any buttons until the next display appeared.

There were three sets of 36 trials that included equal numbers of stimuli with the ball on the left-hand and right-hand sides. During each set about $20 \%$ of the trials were stop trials (i.e. a whistle was heard) while the rest were go trials. There were also 10 practice items. At least two of these 10 practice cases were stop trials. In stop items the time interval between the presentation of a stimulus and the emission of the stop signal cue varied depending on the participant's performance. This procedure ensured that participants would correctly inhibit a response approximately $50 \%$ of the time. When the time interval increased, it was more difficult to correctly suppress a response. Thus, if a participant was performing well in stop trials, the time interval increased until a mistake was made. If the participant's performance was poor, the delay period decreased. The main dependent variable was the Stop Signal Reaction Time (henceforth SSRT). This was calculated by subtracting the average delay period from the average reaction time (henceforth RT) of responses in the go trials. 


\section{The Simon task (Simon, 1969)}

In this computerized test participants were asked to press the right arrow key on the keyboard if a red square appeared on the screen and the left arrow key if a green square was displayed. In congruent trials the square was presented at the same side as the correct key while, in incongruent trials, it appeared on the side opposite to the correct key. In neutral trials the square was displayed at the centre of the screen. The task included two blocks of trials presented in a fixed order. In the first block 24 congruent and 24 incongruent items were randomly intermixed whereas the second block included 48 neutral trials. In both blocks, test trials were preceded by eight practice items. The difference in mean RTs between correct responses in congruent and incongruent trials (Simon effect) was taken as the main indicator of children's inhibition skills.

\subsubsection{Switching test}

\section{The Color-Shape task}

In each item of this online test participants were presented with a display that contained several simultaneous stimuli. The first was the target figure at the centre of the display. This could be either a triangle or a circle and either blue or red. Second, two small figures were shown at the bottom of the display — one at the left and one at the right. Similarly, these figures could be either a triangle or a circle and were either red or blue. Finally, a cue was presented at the top of the display. When the cue was comprised of two small green $X \mathrm{~s}$, the children had to select the small figure that matched the big figure for color (the color game) and when it was made up of two small squares they had to match by shape (the shape game). They were required to respond by pressing either the right or left arrow key on the keyboard. The children had to respond as quickly and as accurately as possible.

The experiment included four blocks of 32 trials which appeared in random order: a pure color and a pure shape block, and two mixed blocks. The two mixed blocks included switches between the two games every two trials. Repeat trials occurred when children repeated the same game as in the previous item while switch trials occurred when participants changed to a different game than the one in the previous trial. Furthermore, half of the test cases in each block were congruent trials and half were incongruent trials. Incongruent items occurred when the shape (in the color game) or the color (in the shape game) of the correct small figure was different from the shape or the color of the target figure.

The switching cost, calculated by subtracting mean RTs in correct repeat trials from mean RTs in correct switch items in the mixed blocks, was taken as the main indicator of 
children's switching skills.

\subsubsection{Fluid intelligence test}

The WASI Matrix Reasoning test (Wechsler, 1999) (henceforth IQ)

This task was administered as a test of participants' non-verbal fluid intelligence.

\section{Results}

\subsection{Preliminary analyses}

\subsubsection{Outlier analysis}

For the RT-based measures only RTs from correct responses were analyzed. Also, to prevent extreme RTs from influencing participants' mean RT scores, the following trimming procedure was performed (cf. Miyake et al., 2000): first the overall distribution of RTs in each task was inspected and lower and upper bound RTs for each task were established. Then every value that exceeded these criteria was substituted with these. The lower and upper bound RTs in this trimming procedure for each task were as follows: 400 and $6000 \mathrm{~ms}$ for the Color-Shape task and 200 and $2500 \mathrm{~ms}$ for the Simon task. ${ }^{\text {iv }}$

\subsubsection{Executive control components}

Measures from each of the five EC tests were submitted to a principal component analysis (henceforth PCA). The analysis was conducted on the whole sample of participants. The following six dependent measures from each task (shown in parentheses) were entered into the analysis: Simon effect (Simon task), switch cost (Color-Shape task), sum of correctly recalled trials in the BDST, sum of correctly recalled trials in the forward and backward conditions of the Corsi Blocks task, and the SSRT (Soccer task).

A PCA was conducted on the six dependent measures with orthogonal rotation (varimax). The analysis indicated that two components had eigenvalues over Kaiser's criterion of 1 and in combination explained $51.67 \%$ of the variance. Table 1 summarizes the PCA results including the factor loadings after rotation. Participants' scores in the forward and backward conditions of the Corsi Blocks task, and in the BDST clustered on the first component, which we interpreted as representing the Working Memory aspect of EC. The switch cost, Simon effect, and SSRT measures, on the other hand, loaded on the second component, which we interpreted as representing the Inhibition aspect of EC. 
Table 1: Summary results of exploratory factor analysis on the six executive control measures.

\begin{tabular}{lcc}
\hline \multicolumn{1}{c}{ Measure } & Rotated Factor Loadings \\
\hline Corsi forward accuracy & $\begin{array}{c}\text { Factor 1: } \\
\text { Working Memory }\end{array}$ & $\begin{array}{c}\text { Factor 2: } \\
\text { Inhibition }\end{array}$ \\
Corsi backward accuracy & $\mathbf{8 0 7}$ & .066 \\
BDST accuracy &. $\mathbf{7 3 9}$ & .210 \\
Simon effect & .744 & -.094 \\
Switch cost & .099 & $\mathbf{. 6 9 2}$ \\
SSRT & .092 & $-\mathbf{6 6 8}$ \\
\hline Eigenvalues & .374 & $\mathbf{. 4 5 7}$ \\
\% of variance & 1.909 & 1.191 \\
\hline
\end{tabular}

Note 1: Factor loadings above .40 appear in bold.

Note 2: Corsi forward=forward condition of the Corsi Blocks task, Corsi backward=backward condition of the Corsi Blocks task, BDST=Backward Digit Span Task, SSRT=Stop Signal Reaction Time.

\subsubsection{Composite scores}

Following the PCA, separate composite scores were computed from the individual WM and Inhibition measures. This allowed us to (1) obtain more reliable and robust indicators of the two EC components, (2) increase the power of the experiment by including more participants since an overall composite score was calculated for a child even if $\mathrm{s} / \mathrm{he}$ had missing data in any of the EC tasks (see Carlson \& Meltzoff, 2008), and (3) decrease the dependent variables and therefore the risk of type I error which becomes higher when performing multiple separate comparisons on the dependent measures of each EC task individually.

The composite scores were calculated for each participant by transforming into $\mathrm{z}$ scores and then averaging the participants' scores in the relevant measures (see Calvo \& Bialystok, 2014; Carlson \& Meltzoff, 2008). Before computing the Inhibition score, the Simon effect, switch cost, and SSRT scores were reversed scored by multiplying with -1 , so that for all measures a higher score indicated better performance.

Finally, in order to reduce the number of control variables entered into the various analyses, composite scores were created (in the same way as above) for background variables that are conceptually related and significantly correlated with each other. Thus, WFVT scoreGreek $^{\mathrm{vi}}$ and language comprehension score-Greek (in CG for bilectals and multilinguals and in SMG for monolinguals) were collapsed into a single score indicating general language 
ability in Greek (henceforth, general language ability-1). This score was used in comparison 1 of the Main Results section. Similarly, in the sample of children who also took the PPVT, the PPVT score-Greek (indicating performance in the CG version of the PPVT for bilectals and in the SMG version for monolinguals) and the general language ability score-1 were again collapsed into a new single indicator of language ability in Greek (henceforth, general language ability-2). This language score was used only in comparison 2 of the Main Results section in order to exert a more reliable statistical control on children's language proficiency in Greek. Furthermore, bilectal children's scores in the SMG version of the PPVT and the language comprehension test were combined into a single measure (language ability-SMG). This allowed to test whether EC performance in bilectals was related to language proficiency in their second, non-native variety. Finally, maternal level of education, paternal level of education, and FAS score were also collapsed into a single measure indicating socioeconomic status (SES).

Before comparing the performance of the three groups, the correlations between the EC scores (WM, Inhibition composite scores) and the various background measures (SES, IQ, age, general language ability-1, and general language ability-2) were examined. The correlations between these variables, besides the general language ability-2 score, were based on the whole sample of participants in this study. The correlations with the general language ability-2 score were based on the sample of 42 children who also took the PPVT. These correlations are presented in table 2. 


\begin{tabular}{|c|c|c|c|c|c|c|}
\hline WM & Inhibition $^{1}$ & Age & Gender & IQ & SES & General language ability-1 \\
\hline $.28^{* *}$ & & & & & & \\
\hline .01 & -.02 & -.03 & & & & \\
\hline $.58^{* *}$ & $.29^{* *}$ & $.57^{* *}$ & .01 & & & \\
\hline $.44^{* *}$ & $.27^{* *}$ & $.53^{* *}$ & -.03 & $.38^{* * *}$ & .08 & \\
\hline $.49^{* *}$ & .1 & $.48^{* *}$ & .17 & .09 & .06 & $.94^{* *}$ \\
\hline
\end{tabular}

**. Correlation is significant at the 0.01 level (2-tailed), *. Correlation is significant at the 0.05 level (2-tailed).

${ }^{1}$ Measures were reversed scored by multiplying with -1 so that a high positive score indicates superior performance.

Note: $\mathbf{W M}=$ Working memory composite score, Inhibition=Inhibition composite score, Age=participants' age in years, IQ=score in the WASI matrix reasoning test, SES=Socioeconomic status composite score, General language ability-1=general language ability composite score (without the PPVT-Greek included in its calculation), General language ability-2=general language ability composite score (with the PPVT-Greek score included in its calculation). 


\subsection{Main analyses}

Comparisons between the three groups were performed in two stages. In the first stage the performance of all groups of children was compared to each other (multilinguals versus bilectals versus monolinguals). To this end, the three groups were matched in age by excluding from the analyses all multilingual and bilectal children who were above nine years or below six years of age.

In the second stage the performance of a subset of 17 bilectal children was compared to that of the monolingual group. All these children were also administered a receptive vocabulary test (PPVT). The receptive vocabulary test was given to the 17 bilectal children in order to test whether exercising a more rigid statistical control over children's language skills would reveal or increase potential bilectal advantages in EC, since both composite EC measures significantly and positively correlated with language ability (see table 2) and bilectal children were (possibly) disadvantaged in language proficiency relative to monolinguals.

Moreover, the two groups in this second set of analyses were equivalent in several background variables (age, gender, IQ, SES, language comprehension in Greek, ethnicity/culture, language of education, and immigration history). In the case that significant differences in favor of bilectals were to emerge in this comparison, that would provide more confidence for the interpretation that the relevant factor affecting EC performance is children's multilingualism/bilectalism and not any other hidden cognitive or sociodemographic factor.

Each comparison stage had the following structure. First, the groups were contrasted on the various background measures. Then, analyses were performed comparing the language groups in the EC composite measures (WM and Inhibition). Between-group analyses on the EC composite scores were conducted with the following variables included as covariates: (1) any background measures for which statistically significant differences were found between the groups compared and (2) any background factors that significantly correlated with the dependent variables. This enabled us to (a) to partial out the influence of any of the background variables on the outcome variables and thus to obtain a purer measure of the effect of interest (language group) and (b) to ensure that any group differences on the background variables were not responsible for the presence or absence of any group differences on the dependent measures. ${ }^{\text {vii }}$ 


\subsubsection{Comparison 1: multilinguals versus bilectals versus monolinguals (matched in age)}

\section{Participants}

In the following analyses the performance of 44 bilectal children (21 boys and 23 girls; ages 6;3-9, mean age 7;6, SD 0;9 years), 26 multilinguals (15 boys and 11 girls; ages 6;2-9, mean age 7;7, SD 0;9 years), and 25 monolinguals (15 boys and 10 girls; ages 6;2-9, mean age 7;4, SD 0;9 years) was compared.

\section{Background measures}

Table 3 reports information about multilinguals' language exposure and use based on the Language Background Questionnaire. Background characteristics of the three groups are presented in table 4.

Table 3: Language characteristics of the multilingual group based on the Language Background Questionnaire in comparison 1.

\begin{tabular}{ccccccccc}
\hline Group & $\mathrm{n}$ & & $\begin{array}{c}\text { AoO } \\
\text { CG }\end{array}$ & AoO En & $\begin{array}{c}\text { CG } \\
\text { Home }\end{array}$ & $\begin{array}{c}\text { En } \\
\text { Home }\end{array}$ & SMG & DoBE \\
\hline Multilinguals & $\mathbf{2 6}$ & Mean & $\mathbf{1 . 9}$ & $\mathbf{9 . 9}$ & $\mathbf{2 . 6}$ & $\mathbf{2 . 5}$ & $\mathbf{2}$ & $\mathbf{. 6}$ \\
& & (SD) & $\mathbf{( 4 . 6 )}$ & $\mathbf{( 2 0 . 6 )}$ & $\mathbf{( 0 . 9 )}$ & $\mathbf{( 0 . 9 )}$ & $\mathbf{( 0 . 9 )}$ & $\mathbf{( . 2 )}$
\end{tabular}

Note: $\mathrm{n}=$ number, $\mathrm{SD}=$ Standard Deviation, $\mathrm{AoO}$ CG=Age (in months) of onset of exposure to Cypriot Greek, AoO En=age (in months) of onset of exposure to English, CG Home=amount of exposure to/use of Cypriot Greek at home (maximum score: 4), En Home=amount of exposure to/use of English at home (maximum score: 4), SMG=total amount of exposure to/use of Standard Modern Greek (maximum score: 4), DoBB=Degree of balanced exposure to/use of CG and English (range from 0 to 1, with 1 indicating more balanced exposure to/use of two languages).

The three groups did not differ statistically in age $(F(2,92)=0.696, p>.05)$, gender $(\mathrm{F}(2,92)=0.587, \mathrm{p}>.05)$, or language comprehension-Greek (in $\mathrm{CG}$ for bilectals and bilinguals, and in SMG for monolinguals; $F(2,92)=0.319, \mathrm{p}>.05)$. Nevertheless, there were significant differences in SES $(\mathrm{F}(2,89)=9.622, \mathrm{p}<.05)$ and IQ $(\mathrm{F}(2,92)=3.377, \mathrm{p}<.05$, partial $\eta^{2}=.07$ ). Regarding the effect of language group on SES, post-hoc pairwise comparisons with Bonferroni correction showed only a significant difference between bilectals and multilinguals in that bilectal children were of a lower SES than multilinguals $(p<.05)$. Turning to the effect of language group on IQ, post-hoc pairwise comparisons with Bonferroni correction applied, showed only a multilingual advantage over monolinguals $(\mathrm{p}<.05)$.

Finally, an ANOVA on vocabulary scores with Group (multilinguals versus bilectals 
versus monolinguals) as a between-subjects factor revealed a significant effect of language group $\left(\mathrm{F}(2,92)=44.183, \mathrm{p}<.05\right.$, partial $\left.\eta^{2}=.5\right)$. Post-hoc pairwise comparisons with Bonferroni correction for multiple comparisons revealed that multilinguals had a significantly lower vocabulary score than both bilectals and monolinguals, and that bilectals performed significantly worse than monolinguals (all $p \mathrm{~s}<.05)$.

Table 4: Descriptive statistics (means and standard deviations) on background measures (raw values) in comparison 1 by language group.

\begin{tabular}{lccccccccc}
\hline Group & $\mathrm{n}$ & & Age & FAS & LoPE & LoME & IQ & $\begin{array}{c}\text { LC- } \\
\text { Greek }\end{array}$ & $\begin{array}{c}\text { WFVT- } \\
\text { Greek }\end{array}$ \\
\hline Bilectals & $\mathbf{4 4}$ & Mean & $\mathbf{7 ; 6}$ & $\mathbf{6}$ & $\mathbf{3}$ & $\mathbf{3 . 2}$ & $\mathbf{1 3 . 8}$ & $\mathbf{0 . 0 8}$ & $\mathbf{3 2 . 4}$ \\
& & (SD) & $\mathbf{( 0 ; 9 )}$ & $\mathbf{( 1 . 9 )}$ & $\mathbf{( 1 )}$ & $\mathbf{( 0 . 8 )}$ & $\mathbf{( 6 . 5 )}$ & $\mathbf{( 0 . 7 )}$ & $\mathbf{( 5 . 2 )}$ \\
Multilinguals & $\mathbf{2 6}$ & Mean & $\mathbf{7 ; 7}$ & $\mathbf{6 . 9}$ & $\mathbf{3 . 8}$ & $\mathbf{4}$ & $\mathbf{1 6 . 4}$ & $\mathbf{0 . 1 7}$ & $\mathbf{1 9 . 8}$ \\
& & (SD) & $\mathbf{( 0 ; 9 )}$ & $\mathbf{( 1 . 8 )}$ & $\mathbf{( 0 . 6 )}$ & $\mathbf{( 0 )}$ & $\mathbf{( 7 . 5 )}$ & $\mathbf{( 0 . 5 )}$ & $\mathbf{( 1 0 . 8 )}$ \\
Monolinguals & $\mathbf{2 5}$ & Mean & $\mathbf{7 ; 4}$ & $\mathbf{5 . 6}$ & $\mathbf{3 . 6}$ & $\mathbf{3 . 7}$ & $\mathbf{1 1 . 8}$ & $\mathbf{0 . 1 7}$ & $\mathbf{3 7 . 8}$ \\
& & (SD) & $(\mathbf{0 ; 9 )}$ & $\mathbf{( 1 . 5 )}$ & $\mathbf{( 0 . 8 )}$ & $\mathbf{( 0 . 6 )}$ & $\mathbf{( 5 )}$ & $\mathbf{( 0 . 4 )}$ & $\mathbf{( 4 . 9 )}$ \\
\hline
\end{tabular}

Note: $n=$ number, Age=participants' age in years, $I Q=$ score in the WASI matrix reasoning test, LCGreek=score in the language comprehension test-Greek (taken in CG by bilectals and multilinguals and in SMG by monolinguals), FAS=score in the Family Affluence Scale, LoPE=Level of Parental Education, LoME=Level of Maternal Education, WFVT-Greek=score in the Word Finding expressive Vocabulary Test (taken in Greek).

\section{Executive control measures}

Descriptive statistics for all RT and accuracy dependent measures, for various difference scores from each EC task, and for the EC composite scores in this comparison are reported by language group in tables $5 \mathrm{a}$ and $5 \mathrm{~b}$. The tables also provide the results of between-group analyses on these measures. Here we only report the between-group comparisons for the EC composite scores.

The WM and Inhibition composite scores significantly correlated with IQ, general language ability -1 , and age (see table 2). A $2 \times 3$ (EC: WM versus Inhibition by Group: multilinguals versus bilectals versus monolinguals) mixed ANCOVA was conducted with EC as a within-subjects factor, Group as a between-subjects factor and IQ, general language ability-1, age, and SES as covariates. The results of this analysis were as follows. First, the effect of Group was significant $\left(\mathrm{F}(2,84)=3.271, \mathrm{p}<.05\right.$, partial $\left.\eta^{2}=.07\right)$, indicating significantly higher EC performance for multilinguals relative to monolinguals $(p<.05$, Bonferroni correction applied) and no significant differences between the other groups (all 
ps $>.05$, Bonferroni correction applied). Second, the Group $\times E C$ interaction was not significant $(F(2,84)=0.744, p>.05)$, suggesting that the multilingual advantage in EC was not specific to WM or Inhibition.

\begin{tabular}{|c|c|c|c|c|c|c|c|c|c|}
\hline \multirow[t]{2}{*}{ Task } & \multirow[t]{2}{*}{ Measure } & \multicolumn{2}{|c|}{$\begin{array}{c}\text { Bilectals } \\
(\mathrm{n}=44)\end{array}$} & \multicolumn{2}{|c|}{$\begin{array}{c}\text { Multilinguals } \\
(\mathrm{n}=22)\end{array}$} & \multicolumn{2}{|c|}{$\begin{array}{c}\text { Monolinguals } \\
(\mathrm{n}=25)\end{array}$} & \multirow[t]{2}{*}{$\mathrm{F}^{3}$} & \multirow[t]{2}{*}{$\begin{array}{l}\text { Effect size } \\
\text { partial } \eta^{2}\end{array}$} \\
\hline & & Mean & SD & Mean & SD & Mean & SD & & \\
\hline \multirow{9}{*}{$\begin{array}{l}\text { Simon } \\
\text { task }\end{array}$} & $\mathrm{WM}^{1}$ & -0.03 & 0.7 & 0.21 & 0.7 & -0.29 & 0.8 & $2.634^{1}$ & .06 \\
\hline & Inhibition $^{1,2}$ & 0.13 & 0.6 & 0.20 & 0.5 & -0.1 & 0.6 & $1.640^{1}$ & .04 \\
\hline & RTs incongruent & 1147.7 & 322 & 924.3 & 176.9 & 1073.6 & 315.4 & $6.290^{1 *}$ & 13 \\
\hline & RTs congruent & 1033.9 & 287.9 & 866.7 & 185.6 & 986 & 296.6 & $3.683^{1^{*}}$ & .08 \\
\hline & RTs centre & 960.2 & 219.6 & 818.8 & 176.7 & 903.3 & 207.8 & $4.511^{1^{*}}$ & .1 \\
\hline & $\%$ correct incongruent & 89.4 & 11.3 & 88 & 9.6 & 92.2 & 7.6 & $0.268^{2}$ & 01 \\
\hline & $\%$ correct congruent & 97.3 & 3.8 & 95.2 & 7.2 & 96.8 & 5.7 & $0.157^{2}$ & .00 \\
\hline & $\%$ correct centre & 93.5 & 7.4 & 93.6 & 4.8 & 93.7 & 5.7 & $0.373^{2}$ & .01 \\
\hline & Simon effect & 113.8 & 160 & 57.7 & 88.8 & 87.6 & 125.9 & $2.373^{1}$ & .05 \\
\hline \multirow{4}{*}{$\begin{array}{l}\text { Soccer } \\
\text { task }\end{array}$} & RTs go & 1278 & 347.6 & 1238.6 & 305 & 1371.9 & 481.4 & $0.244^{1}$ & .01 \\
\hline & Delay & 490 & 166.1 & 468.9 & 165.4 & 492.2 & 165.1 & $\mathbf{0 . 0 3}^{2}$ & .00 \\
\hline & SSRT & 788.1 & 247.6 & 769.9 & 212.5 & 879.7 & 458.5 & $0.278^{1}$ & .01 \\
\hline & $\%$ correct $s t o p$ & 69.9 & 12.2 & 69.2 & 14.5 & 69.8 & 16.1 & $0.120^{2}$ & .00 \\
\hline
\end{tabular}

\footnotetext{
*p<.05

${ }^{1} \mathrm{~F}$ ratio resulting from an ANCOVA with age, IQ, SES, and general language ability-1 as covariates.

${ }^{2} \mathrm{~F}$ ratio resulting from an ANCOVA with IQ, SES, and general language ability-1 as covariates.

${ }^{3}$ Degrees of freedom for the error term range from 80 to 85 depending on how many covariates were included in the analysis and missing values.

Note: $\mathrm{n}=$ number, $\mathrm{SD}=$ Standard Deviation, WM=Working Memory composite score, Inhibition=Inhibition composite score, BDST=Backward Digit Span Task, RT=Reaction Time, incongruent=incongruent trials, congruent $=$ congruent trials, centre $=$ centre trials, $g_{o}=g_{o}$ trials, stop $=$ stop trials, SSRT $=$ Stop Signal Reaction Time, Delay=delay between presentation of visual stimulus and stop signal auditory stimulus in the Soccer task, \% correct=percentage of accurate responses.
} 
Table 5b (continued from the previous page): Descriptive statistics (means and standard deviations) on the EC dependent measures (raw values) in comparison 1 by language group. Results of between-group ANCOVAs on these measures are also reported.

\begin{tabular}{|c|c|c|c|c|c|c|c|c|c|}
\hline \multirow[t]{2}{*}{ Task } & \multirow[t]{2}{*}{ Measure } & \multicolumn{2}{|c|}{$\begin{array}{c}\text { Bilectals } \\
(n=44)\end{array}$} & \multicolumn{2}{|c|}{$\begin{array}{l}\text { Multilinguals } \\
\qquad(\mathrm{n}=22)\end{array}$} & \multicolumn{2}{|c|}{$\begin{array}{l}\text { Monolinguals } \\
\quad(\mathrm{n}=25)\end{array}$} & \multirow[t]{2}{*}{$\mathrm{F}^{3}$} & \multirow[t]{2}{*}{$\begin{array}{l}\text { Effect size } \\
\text { partial } \eta^{2}\end{array}$} \\
\hline & & Mean & $\mathrm{SD}$ & Mean & SD & Mean & SD & & \\
\hline \multirow[t]{5}{*}{$\begin{array}{l}\text { Colour- } \\
\text { Shape Task }\end{array}$} & $\begin{array}{l}\text { RTs repeat (mixed } \\
\text { blocks) }\end{array}$ & 2596.3 & 877.6 & 2504.9 & 659.1 & 2498.3 & 789.8 & $0.076^{1}$ & .00 \\
\hline & RTs switch & 2525.3 & 854.5 & 2516 & 667.8 & 2632.4 & 780.1 & $0.402^{1}$ & .01 \\
\hline & $\begin{array}{l}\% \text { correct repeat } \\
\text { (mixed blocks) }\end{array}$ & 80.4 & 10.6 & 81.1 & 9.8 & 79.5 & 11.1 & $0.420^{1}$ & .01 \\
\hline & $\%$ correct switch & 82 & 12.2 & 83.3 & 13.3 & 79.5 & 9.8 & $\mathbf{0 . 5 3 2} 2^{1}$ & .02 \\
\hline & Switch cost & -71.1 & 324.5 & 11.1 & 360.7 & 134.2 & 341.2 & $3.897^{2 *}$ & .09 \\
\hline BDST & $\mathrm{n}$ correct trials & 4 & 1.2 & 4.5 & 1.4 & 3.8 & 1.2 & $0.662^{1}$ & .02 \\
\hline \multirow{2}{*}{$\begin{array}{l}\text { Corsi } \\
\text { Blocks task }\end{array}$} & Forward n correct trials & 6.1 & 1.9 & 6.5 & 1.2 & 5.4 & 2 & $3.048^{1}$ & .07 \\
\hline & Backward n correct & 5 & 1.8 & 5.3 & 1.8 & 4.6 & 2.1 & $0.887^{1}$ & .02 \\
\hline
\end{tabular}

\footnotetext{
*p<.05

${ }^{1} \mathrm{~F}$ ratio resulting from an ANCOVA with age, IQ, SES, and general language ability-1 as covariates.

${ }^{2} \mathrm{~F}$ ratio resulting from an ANCOVA with IQ, SES, and general language ability-1 as covariates.

${ }^{3}$ Degrees of freedom for the error term range from 83 to 85 depending on how many covariates were included in the analysis and missing values.

Note: $\mathrm{n}=$ number, $\mathrm{SD}=$ Standard Deviation, $\mathrm{RT}=$ Reaction Time, repeat=repeat trials, $\mathrm{switch}=\mathrm{switch}$ trials, BDST=Backward Digit Span Task, \% correct=percentage of accurate responses, Forward=Forward condition, Backward=backward condition.
}

Is the effect of multilingualism on overall EC performance mediated by IQ skills?

EC performance significantly correlated with multilingualism (as evident in the betweengroup analysis on the two EC composite measures), IQ also significantly and positively correlated with multilingualism (as evident in the between-group analysis on IQ), and IQ significantly and positively correlated with both EC measures. This pattern of correlations makes plausible a scenario according to which multilinguals' advanced EC skills were 
mediated by their superior IQ performance (see Field, 2013:408-423). In order to further explore this possibility a mediation analysis was conducted.

The multilingual EC advantage was found in overall EC performance and thus an overall EC composite score was entered as the dependent variable in the mediation analysis. This overall EC composite score was calculated by averaging participants' ( $\mathrm{z}$ transformed) scores in the six main indicators of EC performance. Language group (multilinguals versus monolinguals) was included in the analysis as an independent variable, IQ as a potential mediator, and age, language ability-1, and SES as covariates.

Results indicated a non-significant indirect effect of multilingualism on overall EC performance through IQ $(b=0.0226$, Bias Corrected and Accelerated confidence intervals $(-0.0961,0.0082))$, suggesting that no mediation was present. On the other hand, as already reported in the between-group analysis on the two EC composite measures, the direct effect of language group on overall EC performance was significant even when IQ was included in the analysis as a predictor $(\mathrm{t}(44)=2.1934, \mathrm{p}<.05)$. Thus there was a significant effect of multilingualism (with multilinguals outperforming monolinguals) on overall EC performance that could not be explained in terms of IQ.

\subsubsection{Comparison 2: bilectals versus monolinguals}

The analyses in this section give the opportunity to test for differences in EC between bilectals and monolinguals when more reliably controlling for general language ability. Both the WM and Inhibition composite scores significantly and positively correlated with language ability in Greek (see table 2) and bilectal children exhibited lower performance in a measure of language proficiency targeting expressive vocabulary. This raises the possibility that a bilectal advantage over monolinguals can indeed be found if children's language proficiency in Greek is more rigidly controlled. This more reliable measure of children's language proficiency was obtained by creating a composite score (general language ability-2) from three individual language measures: language comprehension, expressive vocabulary (WFVT), and receptive vocabulary (PPVT).

\section{Participants}

In the following analyses, 17 bilectal children (10 boys and 7 girls; ages 6;3-9, mean age 7;6, SD 0;9 years) and 25 monolingual children (15 boys and 10 girls; ages 6;2-9, mean age 7;4, SD 0;9 years) were included. 


\section{Background measures}

Information about the background characteristics of each language group is reported in table 6. The two groups did not differ in age $(\mathrm{t}(40)=0.868, \mathrm{p}>.05)$, gender $(\mathrm{t}(40)=-.074, \mathrm{p}>.05)$, language comprehension-Greek (when bilectals took the test in CG and monolinguals in SMG: $\mathrm{t}(40)=-0.483, \mathrm{p}>.05)$, IQ $(\mathrm{t}(40)=1.246, \mathrm{p}>.05)$, or SES $(\mathrm{t}(38)=-1.373, \mathrm{p}>.05)$. However, bilectal children had a significantly lower expressive vocabulary score $(\mathrm{t}(40)=-$ 4.365, $\mathrm{p}<.05)$. Similarly, a between-group analysis on receptive vocabulary scores when each group took the PPVT in their native variety (bilectals in CG and monolinguals in SMG) revealed a significant effect of Group in that monolingual children out-performed bilectal children $(\mathrm{t}(40)=-2.212, \mathrm{p}<.05, \mathrm{r}=.3)$.

\begin{tabular}{|c|c|c|c|c|c|c|c|c|c|c|}
\hline \multicolumn{11}{|c|}{ anguage group. } \\
\hline Group & $\mathrm{n}$ & & Age & FAS & LoPE & LoME & IQ & $\begin{array}{c}\text { LC- } \\
\text { Greek }\end{array}$ & $\begin{array}{c}\text { WFVT- } \\
\text { Greek }\end{array}$ & $\begin{array}{l}\text { PPVT- } \\
\text { Greek }\end{array}$ \\
\hline \multirow[t]{2}{*}{ Bilectals } & 17 & Mean & $7 ; 6$ & 5.9 & 3 & 3.3 & 14.1 & 0.1 & 6 & 95 \\
\hline & & (SD) & $(0 ; 9)$ & (2) & (1.1) & (1) & $(7.3$ & (0.4) & (5.6) & (16.4) \\
\hline \multirow[t]{2}{*}{ Monolinguals } & 25 & Mean & $7 ; 4$ & 5.6 & 3.6 & 3.7 & 11.8 & $\mathbf{0 .}$ & 37.8 & 106.4 \\
\hline & & (SD) & 0 ;9) & $.5)$ & $(0.8)$ & (0. & (5) & (0. & 4.9 & 5) \\
\hline \multicolumn{11}{|c|}{$\begin{array}{l}\text { Note: } \mathrm{n}=\text { number, SD=Standard Deviation, Age=age in years, FAS=score in the Family Affluence Scale, } \\
\text { LoPE=Level of Parental Education, LoME=Level of Maternal Education, IQ=score in the WASI matrix } \\
\text { reasoning test, LC-Greek=score in the language comprehension test-Greek (taken in CG by bilectals and } \\
\text { bilinguals and in SMG by monolinguals), WFVT=score in the Word Finding expressive Vocabulary Test } \\
\text { (taken in Greek), PPVT-Greek=score in Peabody Picture receptive Vocabulary Test (taken in CG by } \\
\text { bilectals and in SMG by monolinguals). }\end{array}$} \\
\hline
\end{tabular}

\section{Executive control measures}

Mean scores and standard deviations for the two EC composite measures by language group for this analysis are reported in table 7. A $2 \times 2$ (EC: WM versus Inhibition by Group: bilectals versus monolinguals) mixed ANCOVA with EC as a within-subjects factor, Group as a between-subjects factor and IQ, general language ability-2, and age as covariates revealed a significant effect of Group $\left(F(1,37)=8.186, p<.05\right.$, partial $\left.\eta^{2}=.18\right)$ in that bilectal children outperformed monolinguals. The Group $\times \mathrm{EC}$ interaction was not significant $(\mathrm{F}(1,37)=0.593$, $\mathrm{p}>.05)$. This demonstrates that, like the multilingual advantage, the bilectal advantage is found in overall EC ability and is not specific to a single EC component.

Finally, correlational analyses indicated that the overall WM score in bilectal children significantly correlated with PPVT performance in SMG (i.e. their second, non-native dialect; 
$\mathrm{r}=.74, \mathrm{p}($ two-tailed $)<.05))$ and with the overall language ability-SMG score $(\mathrm{r}=.56, \mathrm{p}$ (twotailed)<.05). Bilectal children's overall inhibition score, on the other hand, did not significantly correlate with any of the language measures in SMG $(r=.32$, $p$ (two-tailed) $>.05$ for PPVT-SMG and r=.14, $\mathrm{p}$ (two-tailed)>.05 for overall language ability-SMG).

\begin{tabular}{lcccc}
\hline $\begin{array}{l}\text { Table 7: Descriptive statistics (means and standard deviations) on } \\
\text { (raw values) in comparison 2 by language group. }\end{array}$ & \multicolumn{3}{c}{$\begin{array}{c}\text { Monolinguals } \\
(\mathrm{n}=25)\end{array}$} \\
\hline Measure & \multicolumn{2}{c}{$\begin{array}{c}\text { Bilectals } \\
(\mathrm{n}=17)\end{array}$} & Mean & SD \\
\hline Mean & SD & 0.7 & -0.29 & 0.8 \\
Inhibition & 0.04 & 0.7 & -0.1 & 0.6
\end{tabular}

Note: $\mathrm{n}=$ number, $\mathrm{SD}=$ Standard Deviation, $\mathrm{WM}=$ Working Memory composite score, Inhibition=Inhibition composite score.

\subsubsection{Power of statistical analyses for the effect of Group in comparisons 1 and 2}

Some of the comparisons reported in the previous sections involve relatively small numbers of participants, and this may give rise to concerns about the sufficiency of the power of the design. Following the recommendation of O'Keefe (2007) that after-the-fact power calculations should be conducted on an effect size of independent interest rather than on the effect size observed in a given study (see also Sun et al., 2011), we calculated the power of our between-group statistical tests on EC to detect a large effect size. This is the magnitude of the bilingualism effect on a combined measure of abstract and symbolic representation, attentional control, and problem solving reported in the meta-analysis of Adesope et al. (2010). These power calculations indicated that the first comparison had a power of .93 for the main effect of Group (for a three by two mixed ANOVA with a total sample of 95 children) and the second comparison had a power of .7 (for a two by two mixed ANOVA with a total sample of 42 participants and unequal-sized groups). Thus, the second comparison had a power close to but below the recommended level of .8 (Cohen, 1988). Nevertheless, these power calculations do not take into account two aspects of our statistical analyses that are known to have a positive effect on power. The first is the use of ANCOVA that allows removing the effect of factors that correlate with the dependent measure of interest (and hence reduces error variance and improves the relationship between Group and the dependent variable). The second is the measurement of the EC construct through multiple indicators that leads to more reliable estimates of this cognitive component (Cohen, 1988:535-542; Rushton 
et al., 1983).

Regarding the first aspect, in our study we identified and measured four factors that are known in the literature to affect EC performance: language ability, SES, IQ, and age (see e.g. Morton \& Harper, 2007; Unsworth et al., 2014; Carlson \& Meltzoff, 2008). Focusing on the second comparison (whose power was found to be close to but below the acceptable limit for a large effect size), a regression analysis of language ability-2, IQ, and age (the factors included in the between-group analysis as covariates) on the overall EC composite score showed that these three variables accounted collectively for $29 \%$ of the total variance in the dependent measure. Using the formula in Cohen (1988:540-541), this means that an ANCOVA comparison with these three factors as covariates would need only $71 \%$ of participants to achieve a power of .8 compared to a comparison without these variables covaried. In essence, this means a gain of 16 participants which brings the power level of the second comparison in this study to .84 , which meets and surpasses the required level of .8 .

We would expect, however, that the above estimates of power are even higher. When multiple measures of a cognitive component are extracted from different tasks and these measures show some degree of convergent validity and are combined into a single indicator of that component, variance idiosyncratic to each task is averaged out and general variance accumulates (see Carlson, 2003; Rushton et al., 1983). This leaves a less biased, more stable, more reliable, and purer estimator of the relevant component (Rushton et al., 1983) and achieves "more psychometric precision" (Carlson, 2003:142). This reduction in error in the dependent measure and consequent increase in reliability is also salutary for power as noted by Cohen, (1988:537; see also references therein).

\section{Discussion}

Previous research has documented positive associations between childhood bilingualism and executive control in that bilingual children outperform monolinguals in EC tasks (e.g. Bialystok et al., 2010; Ahtar \& Menjivar, 2012; Barac et al., 2014). The principal goal of this study was to examine the effect of close typological similarity between the varieties spoken by children on this outcome. We aimed to achieve this by testing whether the widely-reported bilingual advantage in EC can also be found in bilectal children speaking two linguistic varieties (Cypriot Greek and Standard Modern Greek) that are genetically related, show a high degree of lexical and structural overlap, and are considered to be dialects of the same language (Greek). There were several major and minor results of this study and these are 
discussed in the following sections.

\subsection{The components of EC (as emerging in the current study)}

A principal component analysis on six indicators of EC ability revealed two distinct factors that were moderately correlated and were interpreted as representing the Inhibition and WM aspects of the EC construct. These results are roughly compatible with the EC model proposed by Miyake et al. (2000) for adults. Even though the analysis in this study included a measure of switching and this score did not load on a separate third factor - the switching aspect of EC-this result is not necessarily inconsistent with Miyake et al.'s (2000) framework. This is because the mixed blocks of the Color-Shape task posed demands not only on children's switching skills but also on their inhibitory capacity. ${ }^{\text {viii }}$ Besides switching from one game to another, about half of the switch trials required children to ignore irrelevant information in order to achieve accurate performance (see description of task in section 2.2.5). Thus, it is no surprise that the switching cost measure loaded on the Inhibition factor along with the other two inhibition scores (Simon effect and SSRT).

Finally, the results of the PCA in this study suggest that the EC indices extracted from the various tasks showed some degree of convergent validity and were credible indicators of the domain-general cognitive skills they were supposed to measure- the WM and Inhibition aspects of EC.

\subsection{The effects of childhood multilingualism and bilectalism on EC}

The experimental investigation in this paper offered an opportunity to assess the generality of the reported effects of bilingualism on EC by testing two new, previously unstudied groups of children-English-Greek multilingual and CG-SMG bilectal children-in the diglossic society of Cyprus. This study presented some strengths relative to previous research. First, the PCA results documented that the various EC scores used were valid measures of the target EC aspects. Additionally, valid and reliable indicators of each EC component were obtained by forming composite scores from several measures that clustered on each factor. This increased the power of the experiment to detect potential differences between the different language groups.

Indeed, consistent with previous reports (Bialystok, 1999; Carlson \& Meltzoff, 2008; Blom et al., 2014), multilinguals exhibited superior EC performance relative to monolinguals 
after statistically controlling for a number of background factors (IQ, SES, general language ability in Greek, and age). The multilingual advantage was found in overall EC ability and could not be attributed to a specific EC component. This finding, however, was conditional on multilinguals' language proficiency. The positive effect of multilingualism on EC was clearly significant only when statistically adjusting for multilingual children's lower language skills (as well as for differences in other background variables) (for similar results, see also Carlson \& Meltzoff, 2008; Bialystok, 1999; Blom et al., 2014).

The novel and most important contribution of this study, however, is that it showed that these positive multilingual effects on EC extend to children speaking two closely related dialects of the same language. As predicted, bilectal children outscored their monolingual peers in EC performance and did not differ from multilinguals. Nevertheless, the bilectal effect was somewhat weaker than the multilingual advantage and attained statistical significance only after covarying in the analysis a more robust and reliable measure of children's verbal capacity. Similar to multilinguals, this advantage was evident in overall EC skill without a specific EC component being selectively affected.

It is important to emphasize that superior EC performance in bilectals relative to monolinguals was detected only after statistically adjusting for differences between the two groups in language abilities. This, in turn poses some limits to the generalizability of this finding suggesting that the bilectal (just like the multilingual) EC advantage can be found only once bilectal children's weaker language knowledge is controlled.

In qualitative terms, the effects of bilectalism and multilingualism were, in general, quite similar. For both the bilectal and the multilingual group, superior performance was found in overall EC skill, with no EC component specifically affected, and only after partialing out the effect of verbal proficiency. It should be noted, however, that this study was not designed and could not directly answer the question of whether the effect of bilectalism is quantitatively similar to or smaller than that of bilingualism. This is because our multilingual group consisted of children who were bilectal to some extent (although not to the same extent as the purely bilectal group) and included some children who spoke an additional language besides Greek (CG, SMG) and English. Thus, it is up to future research to establish whether the effect of speaking a second dialect differs quantitatively from that of 'pure' bilingualism.

\subsection{The locus of the bilingual/bilectal advantage in EC performance}

Another goal of this study was to test different proposals regarding the cognitive locus of the 
EC performance advantage in bilinguals. The results of this study indicated a multilingual/bilectal advantage over monolinguals that was evident in overall EC ability but not in a specific EC component (WM or Inhibition). Thus, in general, these results provide support to the EC coordination account according to which the bilingual advantage in EC performance is founded upon an enhanced general EC system, without an individual component appearing as decisive (Bialystok, 2011).

\subsection{The role of confounding factors}

In the present investigation extra care was taken in order to control for several variables that correlate with bilingualism and/or that affect cognitive performance by matching the groups on the relevant variables and/or by measuring these variables and excluding them as potential confounds via statistical procedures. Ethnicity, culture, and immigration status were also controlled by default given the groups of children compared (see section 1.5 and Antoniou, 2014).

Socioeconomic status was carefully measured in the two studies and was statistically controlled in the group comparisons where appropriate. Three different indicators of SES were aggregated into a single composite measure of SES. Hence, it seems reasonable to assume that this composite score precisely and reliably measured this socio-demographic facet and that the ANCOVA led to appropriate adjustments of differences between the three groups. Furthermore, in contrast to previous reports (see e.g. Calvo \& Bialystok, 2014), SES was not found to significantly correlate with EC performance in this study. In addition, significant differences in SES were found only between the multilingual and bilectal children. Hence, in the critical comparisons between multilingual and monolingual children, and between bilectal and monolingual children that tested for the effects of main interest, the groups were of comparable SES.

The possibility that the multilingual advantage in EC was due to multilinguals' superior performance in IQ relative to monolinguals can be excluded on several grounds. First, IQ was covaried in all the between-group analyses on EC. According to Miller \& Chapman (2001:45) the application of ANCOVA is unproblematic when the between-group differences on the covariate do not reflect true population differences but can be attributed to chance. A review of the literature reveals that there is no expectation for a bilingual advantage in non-verbal fluid intelligence and the majority of studies that tested this aspect of cognition in bilingual and monolingual children reported a null bilingual effect (see Barac et 
al., 2014; but see Marzecova et al., 2013; Tao et al., 2013). This raises the possibility that the positive effect of multilingualism on IQ in this study was not a true effect and was due to chance.

But even if the multilingual advantage in IQ performance is real does this pose any statistical challenges on the results in this study? Our answer is again no and different arguments can be offered to ground this response depending on one's explanation for why such a benefit in IQ performance is found in multilinguals. If one takes the view that the multilingual advantage in the WASI matrix reasoning test was due to multilinguals' enhanced EC skills, then the results reported in this study indicating a multilingual/bilectal EC advantage are not actually challenged but in fact reinforced. Such an explanation would justify treating IQ as an EC measure. ${ }^{\text {ix }}$ This in turn would lead to even larger effects of multilingualism/bilectalism on overall EC skill.

But what if the multilingual advantage in IQ performance is in non-verbal fluid intelligence per se and is not mediated by multilinguals' superior EC ability? First, there is no basis on which to expect such an advantage and, to our knowledge, no such a hypothesis has been offered in the literature. Second, even if this scenario were true, this would be an intriguing possibility that would be in line with the story that has been told by many researchers about bilingualism and its cognitive effects-i.e. that bilingualism has broader consequences for non-linguistic cognition.

More importantly, however, this possibility does not in any way challenge our conclusion that multilingualism/bilectalism have independent effects on EC. To begin with, even though only a single test of IQ was administered in this study, we can be fairly certain that the score obtained was a reliable and psychometrically precise measure of non-verbal fluid intelligence and thus that appropriate adjustment for between-group differences were made in the ANCOVA. First, the WASI matrix reasoning test is part of a widely-used test whose psychometric characteristics have been investigated and established. For participants' scores in the matrix reasoning test, Wechsler (1999) reports split-half reliability of .96 and test-retest reliability of .72 for the age range in this sample. Second, we also calculated the internal consistency of this score based on the sample of children recruited in the current study. Split-half reliability for the IQ score in our study was .95 , which is quite high (see Field, 2013:715). Moreover, the possibility that the multilingual advantage in EC was due to multilinguals' superior performance in IQ relative to monolinguals was further excluded by conducting a mediation analysis on overall EC performance. This analysis clearly indicated that there was a positive effect of multilingualism on overall EC ability that was not mediated 
and could not be explained by multilinguals' superior performance in the fluid intelligence test.

Finally, in the second comparison of the current study, bilectal and monolingual subgroups were selected so that they did not statistically differ in terms of either SES or fluid intelligence performance. Yet significant differences between the two groups were obtained in EC skills after controlling for language proficiency.

\section{Conclusion}

Overall, the present findings suggest that bilectalism and multilingualism lead to qualitatively similar advantages in EC ability. This is a first step towards establishing that advantages in non-linguistic EC performance arise irrespective of whether one speaks two different and unrelated languages (such as English and Chinese) or two closely related languages or varieties with a high degree of grammatical and lexical similarity (such as Spanish and Italian, Catalan and Italian, or indeed SMG and CG). Having said that, an outstanding question is whether the advantages evidenced in bilectal children are as pronounced as those exhibited by bilingual children and further research may reveal that while typological distance is not implicated in whether an advantage in EC will arise, it may modulate the size of the advantage.

\section{Acknowledgments}

Parts of this research have been funded by an ESF Experimental Pragmatics Network (EuroXPrag) collaborative grant to all authors, an ESRC Experimental Pragmatics Network in the UK (XPrag-UK; RES-810-21-0069), a Cambridge Humanities Grant to the first and fourth authors, and an Alexander Onassis Foundation scholarship for graduate studies to the first author.

\section{References}

Adesope, O. O., Lavin, T., Thompson, T., \& Ungerleider, C. (2010). A systematic review and meta-analysis of the cognitive correlates of bilingualism. Review of Educational Research, 80(2), 207-245.

Akhtar, N., \& Menjivar, J. A. (2012). Cognitive and linguistic correlates of early exposure to more than one language. Advances in Child Development \& Behavior, 42, 41-78.

Antoniou, K. (2014). The effects of childhood bilectalism and bilingualism on executive control and implicature understanding. Unpublished doctoral dissertation, University 
of Cambridge, Cambridge.

Antoniou, K., Katsos, N., Grohmann, K. K., and Kambanaros, M. (2014). Is bilectalism similar to bilingualism? An investigation into children's vocabulary and executive control skills. In W. Orman \& M., J. Valleau (Eds.), Proceedings of the $38^{\text {th }}$ annual Boston University conference on language development (pp. 12-24). Somerville, MA: Cascadilla Press.

Arvaniti, A. (2010). Linguistic practices in Cyprus and the emergence of Cypriot Standard Greek. Mediterranean Language Review 17, 15-45.

Auer, P. (2005). Europe's sociolinguistic unity, or: A typology of European dialect/standard constellations. In N. Delbecque, J. van der Auwera \& D. Geeraerts (Eds.), Perspectives on variation: Sociolinguistic, historical, comparative (pp. 7-41). Berlin: Mouton de Gruyter.

Barac, R., \& Bialystok, E. (2012). Bilingual effects on cognitive and linguistic development: Role of language, cultural background, and education. Child Development, 83(2), 413-422.

Barac, R., Bialystok, E., Castro, D. C., \& Sanchez, M. (2014). The cognitive development of young dual language learners: A critical review. Early Childhood Research Quarterly, 29(4), 699-714.

Best, J. R., \& Miller, P. H. (2010). A developmental perspective on executive function. Child Development, 81(6), 1641-1660.

Best, J. R., Miller, P. H., \& Jones, L. L. (2009). Executive functions after age 5: Changes and correlates. Developmental Review, 29(3), 180-200.

Bialystok, E. (1988). Levels of bilingualism and levels of linguistic awareness. Developmental Psychology, 24(4), 560.

Bialystok, E. (1999). Cognitive complexity and attentional control in the bilingual mind. Child Development, 70(3), 636-644.

Bialystok, E. (2001). Bilingualism in Development: Language, Literacy, and Cognition. Cambridge: Cambridge University Press.

Bialystok, E. (2011). Coordination of executive functions in monolingual and bilingual children. Journal of Experimental Child Psychology, 110(3), 461-468.

Bialystok, E., Craik, F. I., Green, D. W., \& Gollan, T. H. (2009). Bilingual minds. Psychological Science in the Public Interest, 10(3), 89-129.

Bialystok, E., Luk, G., Peets, K. F., \& Yang, S. (2010). Receptive vocabulary differences in monolingual and bilingual children. Bilingualism: Language and Cognition, 13(04), 525-531.

Bialystok, E., \& Senman, L. (2004). Executive processes in appearance-reality tasks: The role of inhibition of attention and symbolic representation. Child Development, 75(2), $562-579$.

Bialystok, E., \& Viswanathan, M. (2009). Components of executive control with advantages for bilingual children in two cultures. Cognition, 112(3), 494.

Blom, E., Küntay, A. C., Messer, M., Verhagen, J., \& Leseman, P. (2014). The benefits of being bilingual: Working memory in bilingual Turkish-Dutch children. Journal of Experimental Child Psychology, 128(0), 105-119.

Calvo, A., \& Bialystok, E. (2014). Independent effects of bilingualism and socioeconomic status on language ability and executive functioning. Cognition, 130(3), 278-288.

Carlson, S. M. (2003). Executive function in context: Development, measurement, theory, and experience. Monographs of the Society for Research in Child Development, 68(3), 138-151.

Carlson, S. M., \& Meltzoff, A. N. (2008). Bilingual experience and executive functioning in young children. Developmental science, 11(2), 282-298. 
Cohen, J. (1988). Statistical power analysis for the behavioural sciences. Hillsdale, NJ: Erlbaum.

Corsi, P. (1973). Human memory and the medial temporal region of the brain. Unpublished doctoral dissertation, McGill University, Montreal.

Costa, A., Hernández, M., Costa-Faidella, J., \& Sebastián-Gallés, N. (2009). On the bilingual advantage in conflict processing: Now you see it, now you don't. Cognition, 113(2), 135-149.

Costa, A., Hernández, M., \& Sebastián-Gallés, N. (2008). Bilingualism aids conflict resolution: Evidence from the ANT task. Cognition, 106(1), 59-86.

Currie, C. E., Elton, R. A., Todd, J., \& Platt, S. (1997). Indicators of socioeconomic status for adolescents: the WHO Health Behaviour in School-aged Children Survey. Health Education Research, 12(3), 385-397.

Cyprus Ministry of Education and Culture (2014). Cyprus Higher Education, Statistics, Graph 4: Number of Foreign Students by Country of Citizenship, 2011-12. Retrieved September 18, 2014, from http://www.highereducation.ac.cy/en/statistics.html

de Abreu, P. M. E. (2011). Working memory in multilingual children: Is there a bilingual effect? Memory, 19(5), 529-537.

de Abreu, P. M. E., Cruz-Santos, A., Tourinho, C. J., Martin, R., \& Bialystok, E. (2012). Bilingualism enriches the poor enhanced cognitive control in low-income minority children. Psychological Science, 23(11), 1364-1371.

Dunn, L. \& Dunn, D. (1981). Peabody Picture Vocabulary Test-Revised. Circle Pines, MN: American Guidance Service.

Duñabeitia, J. A., Hernández, J. A., Antón, E., Macizo, P., Estévez, A., Fuentes, L. J., \& Carreiras, M. (2014). The inhibitory advantage in bilingual children revisited: Myth or reality? Experimental Psychology, 61(3), 234.

Ellefson, M.R., Serpell, Z., \& Parr, T. (2011--2014). Exploring the malleability of executive control. (R305A110932). Grant awarded to the University of Cambridge by the Institute for Educational Sciences, United States Department of Education.

Field, A. (2013). Discovering Statistics Using SPSS (4 ${ }^{\text {th }}$ edition). London: Sage.

Foy, J. G., \& Mann, V. A. (2013). Bilingual children show advantages in nonverbal auditory executive function task. International Journal of Bilingualism, doi:10.1177/1367006912472263.

Garbin, G., Sanjuan, A., Forn, C., Bustamante, J. C., Rodríguez-Pujadas, A., Belloch, V., et al. (2010). Bridging language and attention: brain basis of the impact of bilingualism on cognitive control. NeuroImage, 53(4), 1272-1278.

Garon, N., Bryson, S. E., \& Smith, I. M. (2008). Executive function in preschoolers: a review using an integrative framework. Psychological Bulletin, 134(1), 31-60.

Genesee, F. \& Nicoladis, E. (2007). Bilingual first language acquisition. In E. Hoff and M. Shatz (Eds.), Handbook of language development (pp. 324-342). Malden, MA: Blackwell Publishing.

Goetz, P. J. (2003). The effects of bilingualism on theory of mind development. Bilingualism Language and Cognition, 6(1), 1-16.

Green, D. W. (1998). Mental control of the bilingual lexico-semantic system. Bilingualism: Language and Cognition, 1(2), 67-81.

Grohmann, K. K. and E. Leivada (2012). Interface ingredients of dialect design: Bi- $x$, sociosyntax of development, and the grammar of Cypriot Greek. In A.M. Di Sciullo (Ed.), Towards a biolinguistic understanding of grammar: Essays on interfaces (pp. 239262) Amsterdam: John Benjamins.

Hernandez, M., Costa, A., Fuentes, L. J., Vivas, A. B., \& Sebastian-Galles, N. (2010). The impact of bilingualism on the executive control and orienting networks of attention. 
Bilingualism: Language and Cognition, 13(03), 315-325.

Hernández, M., Martin, C. D., Barceló, F., \& Costa, A. (2013). Where is the bilingual advantage in task-switching? Journal of Memory and Language, 69(3), 257-276.

Hilchey, M. D., \& Klein, R. M. (2011). Are there bilingual advantages on nonlinguistic interference tasks? Implications for the plasticity of executive control processes. Psychonomic Bulletin \& Review, 18(4), 625-658.

Huitema, B. (2011). The Analysis of Covariance and Alternatives: Statistical Methods for Experiments, Quasi-Experiments, and Single-Case Studies. Hoboken, NJ: John Wiley $\&$ Sons.

Joseph, B. D. (2010). Greek, Modern. In K. Brown and S. Ogilvie (Eds.), Concise encyclopedia of languages of the world (pp. 464-467). Amsterdam: Elsevier.

Karyolemou, M. (2006). Reproduction and innovation of communicative patterns in a former-"diglossic" community. In R. Muhr (Ed.), Reproduction and innovation in language and communication in different language cultures/Reproduktionen und Innovationen in Sprache und Kommunikation verschiedener Sprachkulturen (pp. 3956). Vienna: Peter Lang Verlag.

Karyolemou, M., \& Pavlou, P. (2001). Language attitudes and assessment of salient variables in a bi-dialectal speech community Proceedings of the first international conference on language variation in Europe (pp. 110-120). Barcelona: Universitat Pompeu Fabra.

Kovács, Á. M. (2008). Early bilingualism enhances mechanisms of false-belief reasoning. Developmental Science, 12(1), 48-54.

Kovács, Á. M., \& Mehler, J. (2009). Cognitive gains in 7-month-old bilingual infants. Proceedings of the National Academy of Sciences, 106(16), 6556-6560.

Kroll, J. F., \& Bialystok, E. (2013). Understanding the consequences of bilingualism for language processing and cognition. Journal of Cognitive Psychology, 25(5), 497-514.

Kroll, J. F., Dussias, P. E., Bogulski, C. A., \& Valdes Kroff, J. R. (2012). Juggling two languages in one mind: What bilinguals tell us about language processing and its consequences for cognition. In B. Ross (Ed.), Psychology of learning and motivation: Advances in research and theory (pp. 229-262). San Diego, CA: Academic Press.

Labov, W., Ash, S. \& Boberg, C. (2008). The Atlas of North American English. Phonetics, Phonology and Sound Change. Berlin, Boston: De Gruyter Mouton.

Lewis, M. P., Gary F. S., \& C. D., Fennig (Eds.). (2014). Ethnologue: Languages of the world, $\left(17^{\text {th }}\right.$ ed. $)$ Dallas, TX: SIL International. Online version: http://www.ethnologue.com.

Logan, G. D. (1994). On the ability to inhibit thought and action: A user's guide to the stopsignal paradigm. In D. Dagenbach \& T. H. Carr (Eds.), Inhibitory processes in attention, memory, and language (pp. 189-239). San Diego, CA: Academic Press.

Lyovin, A. (1997). An Introduction to the Languages of the World. New York: Oxford University Press.

Mark, M. M., \& Reichardt, C. S. (2009). Quasi-experimentation. The Sage handbook of applied social research methods (pp. 182-213). Thousand Oaks, CA: Sage Publications.

Miller, G. A., \& Chapman, J. P. (2001). Misunderstanding analysis of covariance. Journal of Abnormal Psychology, 110(1), 40.

Martin-Rhee, M. M., \& Bialystok, E. (2008). The development of two types of inhibitory control in monolingual and bilingual children. Bilingualism Language and Cognition 11(1), 81-93.

Marzecova, A., Asanowicz, D., Krivá, L. U., \& Wodniecka, Z. (2013). The effects of bilingualism on efficiency and lateralization of attentional networks. Bilingualism: 
Language and Cognition, 16(3), 608-623.

Mezzacappa, E. (2004). Alerting, orienting, and executive attention: Developmental properties and sociodemographic correlates in an epidemiological sample of young, urban children. Child Development, 75(5), 1373-1386.

Miyake, A., \& Friedman, N. P. (2012). The nature and organization of individual differences in executive functions four general conclusions. Current Directions in Psychological Science, 21(1), 8-14.

Miyake, A., Friedman, N. P., Emerson, M. J., Witzki, A. H., Howerter, A., \& Wager, T. D. (2000). The unity and diversity of executive functions and their contributions to complex "frontal lobe" tasks: A latent variable analysis. Cognitive Psychology, 41(1), 49-100.

Morales, J., Calvo, A., \& Bialystok, E. (2013). Working memory development in monolingual and bilingual children. Journal of Experimental Child Psychology, 114(2), 187-202.

Morton, J. B., \& Harper, S. N. (2007). What did Simon say? Revisiting the bilingual advantage. Developmental Science, 10(6), 719-726.

Namazi, M., \& Thordardottir, E. (2010). A working memory, not bilingual advantage, in controlled attention. International Journal of Bilingual Education and Bilingualism, 13(5), 597-616.

Newton, Brian (1972). The Generative Interpretation of Dialect: A Study of Modern Greek Phonology. Cambridge: Cambridge University Press.

Nicoladis, E. (2008). Why does bilingualism affect language and cognitive development? In J. Altarriba \& R. Heredia (Eds.), An introduction to bilingualism: Principles and practices (pp. 167-181). Mahwah, NJ: Lawrence Erlbaum.

O'Keefe, D. J. (2007). Brief report: post hoc power, observed power, a priori power, retrospective power, prospective power, achieved power: sorting out appropriate uses of statistical power analyses. Communication methods and measures, 1(4), 291-299.

Oller, D. K., \& Eilers, R. E. (2002). Language and Literacy in Bilingual Children. Clevedon: Multilingual Matters.

Paap, K. R. (2014). The role of componential analysis, categorical hypothesising, replicability and confirmation bias in testing for bilingual advantages in executive functioning. Journal of Cognitive Psychology, 26(3), 242-255.

Paap, K. R., \& Greenberg, Z. I. (2013). There is no coherent evidence for a bilingual advantage in executive processing. Cognitive Psychology, 66(2), 232-258.

Paap, K. R., \& Sawi, O. (2014). Bilingual advantages in executive functioning: Problems in convergent validity, discriminant validity, and the identification of the theoretical constructs. Frontiers in Psychology: Language Sciences, 5: 962, doi:10.3389/fpsyg.2014.00962.

Paradis, J. (2011). Individual differences in child English second language acquisition: Comparing child-internal and child-external factors. Linguistic Approaches to Bilingualism, 1(3), 213-237.

Paradis, J., Emmerzael, K., \& Duncan, T. S. (2010). Assessment of English language learners: Using parent report on first language development. Journal of Communication Disorders, 43(6), 474-497.

Poarch, G. J., \& van Hell, J. G. (2012). Executive functions and inhibitory control in multilingual children: Evidence from second-language learners, bilinguals, and trilinguals. Journal of Experimental Child Psychology, 113(4), 535-551.

Poulin-Dubois, D., Blaye, A., Coutya, J., \& Bialystok, E. (2011). The effects of bilingualism on toddlers' executive functioning. Journal of Experimental Child Psychology, 108(3), 567-579. 
Reichardt, C. S. (1979). The statistical analysis of data from non-equivalent group designs. In T. Cook \& D. Campbell (Eds.), Quasi-experimentation: Design \& analysis issues for field settings (pp. 147-205). Boston, MA: Houghton Mifflin.

Renfrew, C. (1995). Word Finding Vocabulary Test, $4^{\text {th }}$ edition. Oxon: Winslow.

Rowe, C., \& Grohmann, K. K. (2013). Discrete bilectalism: Towards co-overt prestige and diglossic shift in Cyprus. International Journal of the Sociology of Language, 224, 119-142.

Rueda, M. R., Fan, J., McCandliss, B. D., Halparin, J. D., Gruber, D. B., Lercari, L. P., \& Posner, M. I. (2004). Development of attentional networks in childhood. Neuropsychologia, 42(8), 1029-1040.

Rushton, J. P., Brainerd, C. J., \& Pressley, M. (1983). Behavioral development and construct validity: The principle of aggregation. Psychological Bulletin, 94(1), 18-38.

Sabbagh, M. A., Xu, F., Carlson, S. M., Moses, L. J., \& Lee, K. (2006). The development of executive functioning and theory of mind a comparison of Chinese and US preschoolers. Psychological Science, 17(1), 74-81.

Salthouse, T. A. (2010). Is flanker-based inhibition related to age? Identifying specific influences of individual differences on neurocognitive variables. Brain and Cognition, 73(1), 51-61.

Shelton, J. T., Elliott, E. M., Matthews, R. A., Hill, B., \& Gouvier, W. D. (2010). The relationships of working memory, secondary memory, and general fluid intelligence: working memory is special. Journal of Experimental Psychology: Learning, Memory, and Cognition, 36(3), 813-820.

Siegal, M., \& Surian, L. (2012). Access to Language and Cognitive Development. New York: Oxford University Press.

Simon, R. (1969). Reactions towards the source of stimulation. Journal of Experimental Psychology, 81, 174-176.

Simos, P. G., Sideridis, G. D., Protopapas, A., \& Mouzaki, A. (2011). Psychometric evaluation of a receptive vocabulary test for Greek elementary students. Assessment for Effective Intervention, 37(1), 34-49.

Sun, S., Pan, W., \& Wang, L. L. (2011). Rethinking Observed Power. Methodology, 7(3), 81-87.

Tao, L., Marzecová, A., Taft, M., Asanowicz, D., \& Wodniecka, Z. (2011). The efficiency of attentional networks in early and late bilinguals: The role of age of acquisition. Frontiers in Psychology, 2: 123, doi: 10.3389/fpsyg.2011.00123.

Terkourafi, M. (2005). Understanding the present through the past: Processes of koineisation in Cyprus. Diachronica, 22(2), 309-372.

Unsworth, N., Fukuda, K., Awh, E., \& Vogel, E. K. (2014). Working memory and fluid intelligence: Capacity, attention control, and secondary memory retrieval. Cognitive Psychology, 71, 1-26.

Vogindroukas, I., Protopapas, A. \& Sideridis, G. (2009). Test of Expressive Vocabulary [in Greek]. Chania: Glafki.

Wechsler, D. (1949). Wechsler Intelligence Scale for Children. San Antonio, TX: Psychological Corporation.

Wechsler, D. (1999). Wechsler Abbreviated Scale of Intelligence (WASI). San Antonio, TX: Pearson Assessment.

Yang, S., Yang, H., \& Lust, B. (2011). Early childhood bilingualism leads to advances in executive attention: Dissociating culture and language. Bilingualism: Language and Cognition, 14(03), 412-422.

Zinbarg, R. E., Suzuki, S., Uliaszek, A. A., \& Lewis, A. R. (2010). Biased parameter estimates and inflated Type I error rates in analysis of covariance (and analysis of 
partial variance) arising from unreliability: Alternatives and remedial strategies. Journal of Abnormal Psychology, 119(2), 307-319. 


\section{NOTES}

${ }^{\mathrm{i}}$ Miyake et al. (2000) use the terms shifting and updating and monitoring of working memory representations instead of switching and working memory which are used here. We use the latter set of terms because these are more commonly used in the literature.

ii According to Ethnologue, "[t]he percentage of lexical similarity between two linguistic varieties is determined by comparing a set of standardized wordlists and counting those forms that show similarity in both form and meaning. Percentages higher than $85 \%$ usually indicate a speech variant that is likely a dialect of the language with which it is being compared. Unlike intelligibility, lexical similarity is bidirectional or reciprocal." (Lewis et al., 2014; see Dialects in the section Language Information). It is not clear, however, why this percentage of lexical similarity is suggested as the cut-off point for distinguishing between dialects and languages.

iii Here and in the remainder of the article, we use the terms bilingual and bilingualism broadly, to encompass individuals who speak any number of additional languages.

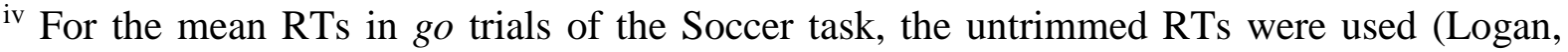
1994).

${ }^{v}$ Morales et al. (2013), Blom et al. (2014), and Calvo and Bialystok (2014) employed a similar task to the Corsi Blocks task in this study - the Frog Matrices Task in the first two studies and the Dot matrix task in the third. Morales et al. (2013) and Calvo and Bialystok (2014) used participants' scores from the forward condition as a measure of WM and found a bilingual advantage in overall performance-i.e. in both the forward and backward conditions - of their test. Blom et al. (2014) reported a bilingual advantage in the forward condition of their task. Both Morales et al. (2013:195) and Blom et al. (2014:115) argue that that the sequential presentation of stimuli requires EC even in the forward condition of visuospatial working memory tests such as the Corsi Blocks task (see also the references cited in the two papers for more evidence in support to this view).

vi We collapse the distinction between $\mathrm{CG}$ and SMG and call the score, expressive vocabulary-Greek because, in the expressive vocabulary test, words coming from both varieties were accepted as correct when testing multilingual and bilectal children.

vii See Field (2013:486) and also Huitema (2011), who note that the independence of the covariate and the experimental effect is not a statistical requirement. When the covariate and the treatment effect are correlated, however, there are cases where the ANCOVA might be biased (e.g. lead to a type I error). Bias in ANCOVA might arise when two groups are known 
and/or are experimentally found to differ on the covariate but the measure used to tap into the confounding variable is not a reliable indicator of that variable (i.e. includes measurement error) (see e.g. Reichardt, 1979, who also describes other sources of bias in ANCOVA that are not relevant here). This situation will lead to an under-adjustment of differences between the two groups. Nevertheless, when bias in the ANCOVA is due to the unreliability of the covariate measure, including the covariate into the analysis is generally better than not including it at all. The inclusion of the covariate will lead to some partial-but possibly not complete-adjustment of differences between the two groups on the covariate (see also Reichardt, 1979; Huitema, 2011; Miller \& Chapman, 2001; Zinbarg et al., 2011, for elaborate discussions of these issues). We will return to this briefly in the Discussion section, where we discuss the issue of confounding factors in our study.

viii In addition to any demands that a switching test by its very nature poses on participants' inhibition skills (see e.g. Garon et al., 2008).

ix See e.g. Carlson \& Meltzoff (2008) who explicitly followed this approach; Miller \& Chapman (2001:47) who seem to suggest it; Carlson \& Meltzoff (2008:288) and Shelton et al. (2010:814) who suggest that performance in nonverbal fluid intelligence tests possibly draws on aspects of EC; and Salthouse (2010) and Paap \& Sawi (2014) who raise the possibility that EC and fluid intelligence are not separable cognitive constructs. 